\title{
Correlation of Embankment Density Degree with Slopes Landslides Safety Factor
}

\author{
Suryanegara Dwipa RS ${ }^{1}$, I Gede Sastra Wibawa ${ }^{2}$, I Nyoman Ramia ${ }^{3}$, I Wayan Wiraga ${ }^{4}$, I Wayan Arya ${ }^{5}$ \\ Civil Department \\ Bali State Polytechnic \\ Jimbaran, Bali \\ ${ }^{1}$ suryanegaradwipars@yahoo.com
}

\begin{abstract}
The purpose of this study was to find the relationship between density $D$ and safety factor SF of the embankment against landslides. If the relation between $D$ and SF is known, then we could simplify the slope stability calculation. The safety factor against landslides could be determined by only entering the degree of density. Calculation of slope stability does not need to be done repeatedly for every given of density degree. In addition, the results of this study can also be used to determine the minimum density level that must be prepared to obtain safety factor number that are still within the allowable safety number limits. The safety factor for landslides is calculated by the Simplified Bishop Method. The required soil parameter data are the value of $\gamma, \phi$ and $\mathbf{c}$, which are obtained from the soil testing results in the laboratory. The method that will be used in this study is by conducting a series of density and soil shear strength tests in the laboratory, to obtain the soil parameters needed as data in analyzing the relationship between D and SF. First, a standard compaction test is carried out on samples that have been prepared, to get the maximum dry density ( $\gamma_{\mathrm{d}}$ maks). Then the samples are made with different density degrees $D$, then conducting direct shear test to get the appropriate values of $\mathrm{c}$ and $\phi$. The soil parameters obtained from the test results in this laboratory are used to determine the safety factor SF based on the Simplyfied Bhisop equation using Geo-5 program. Furthermore, variations in SF values with $D$ were analyzed statistically to obtain a relationship between D and SF. The slope stability calculation with Geo-5 program, shows that there is an increase in safety factor SF against landslides, with increasing degrees of density $D$. In other words, it can also be said that between $D$ and $S F$ are linearly related. The relationship between $D$ and $S F$ is expressed by $S F=0.033 D-2.215$, where $D$ value is expressed in percent.
\end{abstract}

Keywords-Degree of Density; Slope Stability; Safety Factor

\section{INTRODUCTION}

Stability against landslides from a landfill slope is calculated by trying several landslide curves to get the most critical landslide curve. Slope stability will depend on soil strength parameters, namely the value of soil density $\gamma$, shear angle $\phi$ and cohesion value c, obtained from the test results in the laboratory. Different soil strength parameter values will produce different slope stability. In other words, different soil parameters will produce different safety factor against landslides. In soil compaction work, it is difficult to get the value of field density $\left(\gamma_{\text {lap }}\right)$, which corresponds to the value of the laboratory density $\left(\gamma_{\mathrm{lab}}\right)$. So that the field density $\gamma_{\mathrm{lap}}$, is permitted to have a value between $95 \%$ to $100 \%$ of the laboratory density $\gamma_{\text {lab. }}$ Or in other words, the ratio between field densities and laboratory densities is permitted between $95 \%$ to $100 \%$. Thus, in the process of compaction, there will be

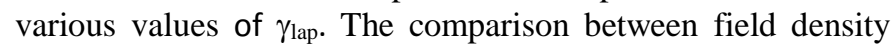
and laboratory density is called degree of density D.

In order to calculate the safety factor of the embankment SF, each value of $\gamma_{\text {lap }}$ obtained must then be tested in a laboratory to determine its $\mathrm{c}$ and $\phi$ values. These three parameters are then entered into the Bishop equation to calculate SF. Although this SF calculation can be done quickly with the help of a computer program, to get the required soil parameters requires a long and time-consuming process, because it must be tested in the laboratory first. For practical purposes, a simpler method is needed to calculate SF. If we can determine the correlation between the degree of density D and safety factor SF, then the process of calculating slope stability analysis can be simplified. The correlation between D and SF that will be searched through this research can also be used to determine what is the minimum $\mathrm{D}$ value that must be prepared in the field so that the embankment has an planned SF value.

\section{LITERATURE REVIEW}

\section{A. Soil Compaction}

If the soil will be used as an embankment material, the soil must be compacted first. The purpose of compaction is to increase soil strength, reduce compression, reduce permeability and reduce changes in volume due to changes in water content, especially in clay soils [1]. The level of soil density is measured by the value of the dry weight $\left(\gamma_{d}\right)$. This dry weight indicates the ratio of dry weight of soil granules per unit volume of soil. Although the soil moisture content changes, the $\gamma_{\mathrm{d}}$ value will remain as long as the total volume of soil does not change. In the process of soil compaction, an amount of water is added to the soil so that the soil grains easily move with each other to achieve a denser condition. The more amount of water, the easier the soil grains move with each other so that the dry weight of $\gamma_{d}$ becomes larger. In the moisture content that is greater than a certain water content, adding the amount of water actually reduces the weight of the dry content. This is because the water fills the soil pore filled with the previous soil 
grains. So that in the process of soil compaction, a certain moisture content $\left(\omega_{\mathrm{opt}}\right)$ will be obtained which will produce the maximum $\gamma_{d}$ mak. To determine the relationship between moisture content and weight of dry soil, soil compaction tests were carried out in the laboratory using the Proctor method. The result of this compaction test is the optimum moisture content $\omega_{\mathrm{opt}}$ and maximum dry unit weight $\gamma_{\mathrm{d} \text { mak }}$.

In the process of soil compaction in the field, the dry weight of the field will be obtained ( $\gamma_{d}$ lap). Control of density levels in the field, is done by comparing between $\gamma_{d}$ lap and $\gamma_{d}$ lab. The ratio between $\gamma_{d}$ lap and $\gamma_{d}$ lab is called the degree of density $\mathrm{D}$, expressed in percent. Common practice in carrying out compaction work, the minimum $\mathrm{D}$ value is required by $95 \%$. That is, $\gamma_{\mathrm{d}}$ lap is allowed to range from $95 \%$ to $100 \%$ of $\gamma_{\mathrm{d}}$ lab.

\section{B. Slope Stability}

There are several methods that can be used to calculate the safety number of a slope. One of them is the Simplified Bishop's method. This method was chosen because it can provide a geometrical shape of the landslide area that is close to the geometry shape of the landslide that occurs. In this Bishop method, a potential landslide surface is described as a circular arc, cantered on $\mathrm{O}$ with radius $\mathrm{r}$. The soil mass above the landslide plane is divided into several segments with width $\mathrm{b}$, as shown in Figure 1. The base of each segment is considered a straight line. The segment base forms an angle of $\alpha$ to the horizontal line and the height of the segment $h$ is measured on the segment axis. By taking the moment to the center of the landslide plane $\mathrm{O}$, the moments due to shear forces (the component weight of soil $\mathrm{W}$ parallel to the landslide plane) must be equal to the moment due to the weight of the soil mass.
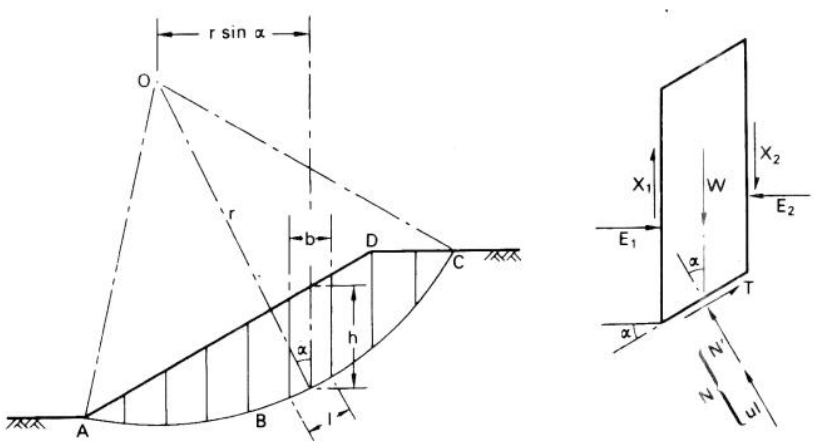

Fig. 1. Simplified Bhisop Method [4]

The general equation for the Bishop's safety factor against landslides [4] is given below, where $\mathrm{W}$ is the weight of the soil segment, $\mathrm{c}$ is cohesion, $\mathrm{b}$ is the width of the segment, $\alpha$ is the angle of the segment base to the horizontal and $\phi$ is internal shear angle of soil.

$$
F=\frac{1}{\sum W \sin \alpha} \sum\left[\left\{c^{\prime} b+(W-u b) \tan \phi^{\prime}\right\} \frac{\sec \alpha}{1+\frac{\tan \alpha \tan \phi^{\prime}}{F}}\right]
$$

Since $\mathrm{F}$ is on the left and the right side of the equation, then iteration is used to calculate the $\mathrm{F}$ value. To speed up the calculation process, computer program is used.

\section{RESEARCH METHOD}

This research is experimental which will be carried out through a series of tests in the laboratory to obtain the soil parameters needed as data in analyzing the relationship between D and SF. Research will be carried out with the following steps :

1. Taking disturbed soil samples in the field.

2. Conducting compaction test to get $\omega_{\text {opt }}$ and $\gamma_{\text {dmak }}$.

3. Conduct a compaction test to get a range of $\mathrm{D}$ values between $95 \%$ to $100 \%$.

4. Conduct direct shear tests on soil samples in $\omega_{\mathrm{opt}}$ and $\gamma_{\mathrm{dmak}}$ conditions and in soil samples with a range of $\mathrm{D}$ values between $95 \%$ to $100 \%$ to obtain soil shear strength parameters at $95 \%$ to $\gamma_{\mathrm{dmak}}$. Get $\mathrm{c}$ and $\phi$ values for the appropriate $\mathrm{D}$ values

5. Determine $S F$ for each value of $\mathrm{D}$, using Geo-5 program

6. Data analysis to find the correlation between D and SF

\section{RESULTS}

\section{A. Compaction Test Result}

TABLE I. STANDARD PROCTOR COMPACTION TEST RESUlt

\begin{tabular}{|c|c|c|}
\hline Soil Parameter & & Unit \\
\hline Gs & 2.654 & \\
\hline$\gamma_{\mathrm{b} \text { mak }}$ & 1.220 & $\mathrm{~g} / \mathrm{cm}^{3}$ \\
\hline$\omega_{\mathrm{opt}}$ & 14.0 & $\%$ \\
\hline
\end{tabular}

B. Direct Shear Test Result

TABLE II. SHEAR STRENGTH SOIL PARAMETER

\begin{tabular}{|c|c|c|c|c|}
\hline \multirow{2}{*}{ No } & $\boldsymbol{\gamma}_{\mathbf{b}}$ & $\mathbf{D}$ & $\mathbf{c}$ & $\boldsymbol{\phi}$ \\
\cline { 2 - 5 } & $\mathbf{g} / \mathbf{c m}^{\mathbf{3}}$ & $\boldsymbol{\%}$ & $\mathbf{K g} / \mathbf{c m}^{\mathbf{2}}$ & $\boldsymbol{d e r}$ \\
\hline 1 & 1.098 & 90.0 & 0.005 & 24.20 \\
\hline 2 & 1.115 & 91.4 & 0.012 & 26.40 \\
\hline 3 & 1.126 & 92.3 & 0.018 & 28.60 \\
\hline 4 & 1.132 & 92.8 & 0.022 & 30.80 \\
\hline 5 & 1.139 & 93.4 & 0.030 & 32.67 \\
\hline 6 & 1.149 & 94.2 & 0.030 & 32.67 \\
\hline 7 & 1.171 & 96.0 & 0.030 & 32.67 \\
\hline 8 & 1.176 & 96.4 & 0.030 & 32.67 \\
\hline 9 & 1.198 & 98.2 & 0.030 & 32.67 \\
\hline 10 & 1.220 & 100.0 & 0.030 & 32.67 \\
\hline
\end{tabular}




\section{Correlation Between D and SF}

TABLE III. CORRELATION D AND SF

\begin{tabular}{|c|c|c|}
\hline No & D & SF \\
\hline 1 & 90.00 & 0.76 \\
\hline 2 & 91.40 & 0.80 \\
\hline 3 & 92.30 & 0.84 \\
\hline 4 & 92.80 & 0.85 \\
\hline 5 & 93.40 & 0.87 \\
\hline 6 & 94.20 & 0.94 \\
\hline 7 & 96.00 & 0.95 \\
\hline 8 & 96.40 & 0.98 \\
\hline 9 & 98.20 & 1.04 \\
\hline 10 & 100.00 & 1.08 \\
\hline
\end{tabular}

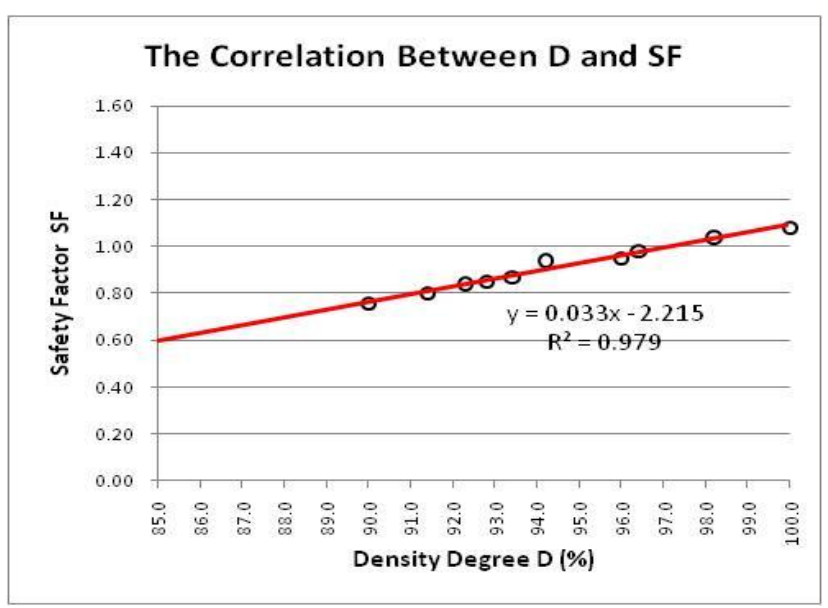

Fig. 2. The Correlation Between D and SF
The analysis of the relationship between D and SF shows that there is a linear relationship between D and SF. The SF value increases, along with an increase in the value of $\mathrm{D}$. The relationship between $\mathrm{D}$ and $\mathrm{SF}$ is expressed by the equation $\mathrm{SF}=0.033 \mathrm{D}-2.215$.

Since the soil sample used in this study is sandy soil, which is coarse-grained soil, it is necessary to do furthermore research for various types of sandy soil to determine the relationship between D and SF for various types of sandy soil. Considering that coarse-grained soils have different physical and mechanical properties from fine-grained soils, the same research also needs to be done for fine-grained soils, represented by clay soils, in order to determine the relationship between D and SF in fine granular soils.

\section{ACKNOWLEDGMENT}

I would like to say thank you for my colleagues at Geotechnical Engineering Department of Bali State Polytechnic for their support to make this research complete. I would like also to give my appreciation to Mrs. Lilik Sudiajeng, the head of research department Bali State Polytechnic for the encouragement to do this research. For the authors of the book I use as reference, I am also very grateful.

\section{REFERENCES}

[1] H.C. Hardiyatmo, Mekanika Tanah 1 dan 2. Yogyakarta: Gajah Mada University Press, 2006.

[2] L.D. Wesley, Mekanika Tanah, Yogyakarta: Penerbit Andi, 2017.

[3] L.D. Wesley, Mekanika Tanah Untuk Tanah Endapan dan Residu, Yogyakarta: Penerbit Andi, 2010.

[4] R.F. Craig and B. Susilo, Mekanika Tanah, 4th ed., Jakarta: Penerbit Airlangga, 1991. 